\title{
Zika highlights need for ethical framework for developing vaccines for pregnant women
}

\author{
Gareth lacobucci
}

The BMJ

The recent outbreak of Zika virus infection highlights the need to prioritise the development and evaluation of vaccines for pregnant women, says a viewpoint article published in the JAMA. ${ }^{1}$

Zika virus is the third recent global infectious disease outbreak, following closely behind H1N1 flu and Ebola virus, that has had detrimental implications for pregnant women and their unborn children.

Saad Omer, of the department of global health at Emory University, Atlanta, and Richard Beigi, of the department of obstetrics, gynaecology, and reproductive sciences at Magee-Women's Hospital of the University of Pittsburgh, argued that, given the recent potential detrimental effect that Zika virus infection is believed to have for fetal development, public health policy and research must overcome the current barriers to developing vaccines for pregnant women and those of reproductive age.

These barriers include the lack of a broadly accepted ethical framework and definition of risk for guiding clinical research during pregnancy, they said, which "has a limiting effect on both academic and industry-led clinical trials."

They also argued that institutional review boards often classified research involving pregnant women as high risk without considering the balance between the potential benefits and the risks, and they called for a "pregnancy-specific ethical framework" to be set up to guide investigators and review boards.
In addition, they called for more baseline data to assess risks and benefits of vaccines against emerging infections in different geographical locations, particularly in the context of infections, such as malaria, associated with adverse birth outcomes.

The article also identified as a barrier the current gap in knowledge concerning vaccine responses in early pregnancy, with limited data available from trials involving women in the first and early second trimesters. The authors argued that more clinical research into vaccine administration before pregnancy or in early pregnancy might be of benefit in the case of Zika virus, because a substantial part of the virus's harmful effects might occur in this period.

Other obstacles the article cited were the lack of consistent guidance on drug and vaccine labels and the absence of standard definitions for measuring outcomes when evaluating vaccine safety studies involving pregnant women.

But the authors emphasised, "These barriers are surmountable with concerted efforts and leadership."

They added, "Strategic planning and action have allowed for advances in paediatric drug development and provide a good model. However, the time to act is now, before the next epidemic takes its toll."

1 Omer SB, Beigi RH. Pregnancy in the time of Zika: addressing barriers for developing vaccines and other measures for pregnant women. JAMA 2016;24. doi:10.1001/jama. 2016.2237.

Published by the BMJ Publishing Group Limited. For permission to use (where not already granted under a licence) please go to http://group.bmj.com/group/rights-licensing/ permissions 
Figure

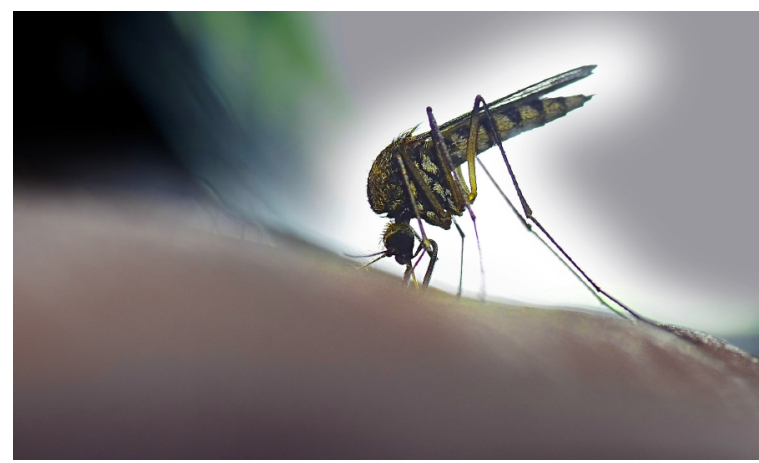

